\title{
Effects of GnRH immunization on the reproductive axis and thymulin
}

\author{
Shiping Su, Xiaoxia Sun', Xiuhong Zhou², Fuigui Fang and Yunsheng Li \\ College of Animal Sciences and Technology, Anhui Agricultural University, 130, Changjiang West Road, \\ Hefei, Anhui 230036, People's Republic of China \\ ${ }^{1}$ College of Life Science, Fujian Agriculture and Forestry University, Fuzhou 350002, People's Republic of China \\ ${ }^{2}$ The Biotechnology Center of Anhui Agriculture University, Hefei, People's Republic of China
}

Correspondence

should be addressed

to F Fang

Email

fgfang@ahau.edu.cn

\begin{abstract}
The bidirectional regulation of thymulin in the reproductive-endocrine function of the hypothalamic-pituitary-gonadal (HPG) axis of rats immunized against GnRH remains largely unclear. We explored the alterations in hormones in the HPG axis in immunized rats to dissect the repressive effect of immunization on thymulin, and to clarify the interrelation of reproductive hormones and thymulin in vivo. The results showed that, in the first 2 weeks of booster immunization, thymulin was repressed when reproductive hormones were severely reduced. The self-feedback regulation of thymulin was then stimulated in later immune stages: the rising circulating thymulin upregulated $\mathrm{LH}$ and $\mathrm{FSH}$, including $\mathrm{GnRH}$ in the hypothalamus, although the levels of those hormones were still significantly lower than in the control groups. In astrocytes, thymulin produced a feedback effect in regulated GnRH neurons. However, in the arcuate nucleus (Arc) and the median eminence (ME), the mediator of astrocytes and other glial cells were also directly affected by reproductive hormones. Thus, in immunized rats, the expression of glial fibrillary acidic protein was distinctly stimulated in the Arc and ME. This study demonstrated that thymulin was downregulated by immunization against $G n R H$ in early stage. Subsequently, the self-feedback regulation was provoked by low circulating thymulin. Thereafter, rising thymulin levels promoted pituitary gonadotropins levels, while acting directly on $G n R H$ neurons, which was mediated by astrocytes in a region-dependent manner in the hypothalamus.
\end{abstract}

\author{
Key Words \\ - thymulin \\ - active immunization \\ - hypothalamic-pituitary- \\ gonadal axis \\ - gonadotrophin-releasing \\ hormone \\ - astrocyte
}

Journal of Endocrinology (2015) 226, 93-102

\section{Introduction}

Thymulin consists of a biologically inactive nonapeptide component termed FTS (an acronym for serum thymus factor in French) coupled in an equimolecular ratio to a zinc ion (Gastinel et al. 1984), which confers biological activity to the molecule (Dardenne et al. 1982). The FTS peptide, whose amino acid sequence is, pyroGlu-Ala-LysSer-Gln-Gly-Gly-Ser-AsnOH, is exclusively produced by thymic epithelial cells (TEC) and is highly conserved in mammals (Dardenne et al. 1974, Bach \& Dardenne 1989). The secretion of thymulin seems to be dependent on the complex neuro-endocrine-immune (NEI) network (Reggiani et al. 2009a). Data have now accumulated that demonstrate strongly that several neuropeptides can regulate the endocrine function of the thymus. Opioids can significantly increase the levels of thymulin in the culture supernatants of TEC in a dose-dependent manner, and the effects were abrogated by an opioid receptor antagonist (Savino et al. 1990). Two studies showed that treatment of old mice with hypothalamic extracts from young mice resulted in reappearance of detectable levels of

Published by Bioscientifica Ltd. 
circulating thymulin, which may represent the evidence that hypothalamic factors influence thymulin production by direct action on TECs (Goya et al. 1995). Some pituitary hormones can influence thymulin synthesis and secretion. Prolactin (PRL) can induce a specific increase in thymulin synthesis and secretion in vivo, and this stimulatory effect was also observed in primary cultures of human and mouse TECs (Dardenne et al. 1989). These data demonstrated that production and secretion of thymulin is influenced directly or indirectly by the hypothalamicpituitary-gonadal (HPG) axis. However, there are few data about the effect of gonadal steroid hormones on thymulin.

As a key signaling molecule, thymulin has multiple influences in the NEI network, which in turn, produces feedback regulation on the HPG axis. In thymulin deficient nude mice, morphometric analysis revealed that athymic nudes have reduced numbers of brain gonadotropin-releasing hormone $(\mathrm{GnRH})$ neurons and pituitary gonadotropic cells, compared with heterozygotes, and neonatal thymulin gene therapy could prevent these changes (Reggiani et al. 2009b, 2012, Martines et al. 2011). Other studies suggested that thymulin stimulates luteinizing hormone (LH) and follicle stimulating hormone (FSH) release from perfused rat pituitaries (Brown et al. 2000, Hinojosa et al. 2004). Moreover, thymulin could augment LH-mediated stimulation of androgen increases in vitro and in vivo in boar testis (Wise \& Ford 1999). These results suggested that thymulin plays a relevant physiological role in the HPG axis.

Generally, glial cells have been viewed as having only structural or support roles in the brain. However, there is increasing evidence that astrocytes also have a neuroregulatory role, as mediators between the signaling molecule and targeting neurons. They also regulate GnRH secretion both by activating the growth factors acting via receptors with tyrosine kinase activity and by inducing plastic rearrangements of glial-GnRH neuron adhesiveness (Ojeda et al. 2008). Studies demonstrated that the ability of transforming growth factor $\alpha$ (TGF $\alpha$ ) to enhance GnRH release depends on the potentiating interaction of PGE2 with these additional glial-derived molecules. In addition, $17 \beta$-estradiol can enhance TGF $\beta_{1}$ release from hypothalamic astrocytes to increase the secretion of GnRH neurons, which provide further evidence that astrocytes have important neuroregulatory capabilities that are subject to endocrine regulation (Ma et al. 1997, Buchanan et al. 2000). Perhaps not surprisingly, as an endocrine hormone, thymulin should regulate the GnRH secretion, mediated by glial cells in the hypothalamus.
GnRH produced in the hypothalamus stimulates the release of gonadotropins from the pituitary, thereby controlling steroidogenesis, gametogenesis and other sex-related characteristics (Gore 2002). GnRH appears to not only have a central effect in the process of reproduction, but also is involved in the regulation of the immune response (Marchetti et al. 2000). Thus, GnRH is one of the most important signaling molecules in neuroendocrine and immune interactions (Marchetti et al. 1998). Recently, with the cloning and sequencing of the GnRH and GnRH receptor (GnRHR), mRNA transcripts encoding GnRH and GnRHR have been detected in rodent thymocytes and TECs (Morale et al. 1991, Weesner et al. 1997), suggesting that GnRH could regulate T-cell development in an autocrine or paracrine manner, and might influence the endocrine function of TECs, including the production of thymulin.

Active immunization of animals against GnRH directly causes a loss of synthesis and secretion of both pituitary gonadotropins and gonadal steroids in the gonads (Einarsson et al. 2009). When used to immunize males, the GnRH vaccine was developed primarily to control immunocastration and to improve the quality of meat (Cook et al. 2000, Miller et al. 2008), based on the interference of endocrine function. In humans, the GnRH vaccine is likely to impede the growth of androgendependent prostatic carcinoma or other hormone-dependent tumors (Ladd et al. 1995, Junco et al. 2008). Thus, endocrine homeostasis is disrupted in the short or longterm in the GnRH-immunized animal, while this disordered endocrine environment is bound to influence thymulin synthesis and secretion in vivo. Conversely, changes in thymulin levels could, in turn, be part of a feedback regulation on the HPG axis. In the present study, we correlated thymulin levels in serum with gonadotropin in GnRH-immunized male rats, and analyzed the thymulin alteration with GnRH and glial fibrillary acidic protein (GFAP) in hypothalamus. We demonstrated the effect of active immunization on the reproductive endocrine and immune endocrine functions of male rats.

\section{Materials and methods}

\section{Animals, immunization protocol and sample collection}

Three-week-old male Sprague-Dawley rats were purchased from the Experimental Animal Center of Anhui Medical University and kept in the animal house at the Anhui Agriculture University (Hefei, P R China). Rats were housed at three per cage in a controlled temperature

Published by Bioscientifica Ltd. 
$\left(22^{\circ} \mathrm{C}\right)$ room and with a $12 \mathrm{~h}$ light: $12 \mathrm{~h}$ darkness cycle. Food and water were available ad libitum. The study was conducted strictly in accordance with the guidelines set by the China Council on Animal Care. Three-week-old male rats were divided randomly into two groups $(n=37$ per group). One group received GnRH-tandem-ovalbumin (GnRH-tandem-OVA, ShineGene Molecular Biotech, Shanghai, China) mixed with $\mathrm{Al}(\mathrm{OH})_{3}$ adjuvant (Sigma), and the other group received equivalent $\mathrm{Al}(\mathrm{OH})_{3}$ adjuvant as the control. According to the results of preliminary experiments, rats were injected subcutaneously at four sites on their backs with $500 \mu \mathrm{l}(200 \mu \mathrm{g}$ peptides/ml $)$ antigen and vehicle, and received boosts with same volume at 5- (300 $\mu \mathrm{g}$ peptides $/ \mathrm{ml})$ and 7 - $(400 \mu \mathrm{g}$ peptides/ml) weeks-old.

Before immunization, at 3-, 5- and 7-weeks-old, eight rats were randomly selected and $1 \mathrm{ml}$ of blood was sampled from the jugular vein in each group for hormone and antibody analysis. After the final booster immunization, eight rats were randomly taken from each group at 2-week intervals for 8 weeks. Animals were anaesthetized with $1 \%$ sodium pentobarbital $(1.0 \mathrm{ml} / 100 \mathrm{~g}$ body weight). Blood was then taken for hormone analysis via cardiac puncture, following which the hypothalami were collected for ELISA detection. At the last sample point, another five rats were sacrificed by anesthesia and cardiac perfusion with 4\% paraformaldehyde (PFA, Sigma-Aldrich) in $0.1 \mathrm{M}$ PBS ( $\mathrm{pH}=7.4$; Invitrogen) was performed in each group. The hypothalami were separated according to Paxinos \& Watson (2000), postfixed for $4 \mathrm{~h}$ in the same fixative solution, and cryoprotected in 30\% sucrose (SigmaAldrich) in 0.1 M PBS until tissues sank to the bottom.

\section{RIA}

Levels of FSH, LH and testosterone in serum were quantified using iodine $\left[{ }^{125} \mathrm{I}\right]-\mathrm{FSH},\left[{ }^{125} \mathrm{I}\right]-\mathrm{LH}$ and $\left[{ }^{125} \mathrm{I}\right]$-testosterone rat-specific RIA kits (Furui Bioengineering Corporation, Beijing, China), according to the manufacturer's instructions. The intra- and inter-assay coefficients of variation for $\mathrm{FSH}, \mathrm{LH}$ and testosterone were all 8 and $13 \%$ respectively. The cross-reactivity of $\left[{ }^{125} \mathrm{I}\right]$-testosterone to dihydrotestosterone and androstenedione was $1.1 \times 10^{-4}$ and $1.2 \times 10^{-7}$ respectively.

\section{ELISA}

The specific GnRH antibodies in rats immunized with GnRH were tested using a previously published ELISA (Jinshu et al. 2005). Briefly, 96-well plates (Thermo Fisher
Scientific, Shanghai, China) were coated with $100 \mu \mathrm{l} /$ well of GnRH-tandem-OVA protein $(10 \mu \mathrm{g} / \mathrm{ml})$ in PBS, and kept at $4{ }^{\circ} \mathrm{C}$ overnight. Wells were blocked with $200 \mu \mathrm{l} /$ well $3 \%$ (w/v) BSA (Sigma) in PBS at $37^{\circ} \mathrm{C}$ for $1.5 \mathrm{~h}$, washed three times with PBS containing 0.05\% Tween-20 (PBST), and incubated with $100 \mu \mathrm{l}$ a of 1:100 dilution of individual sera obtained from immunized rats for $1 \mathrm{~h}$ at $37^{\circ} \mathrm{C}$. The sera were removed, the plates were washed three times, and then incubated with $100 \mu \mathrm{l} /$ well HRP-conjugated goat anti-rat IgG secondary antibody diluted at 1:3000 (sc-2032, Santa Cruz) with PBST, and incubated for $1 \mathrm{~h}$ at $37^{\circ} \mathrm{C}$. After washing, the plates were reacted with $3,3^{\prime}, 5,5^{\prime}$ tetramethyl benzidine (TMB) and hydrogen peroxidase as a substrate. The reaction was stopped with $50 \mu \mathrm{l} /$ well of $\mathrm{H}_{2} \mathrm{SO}_{4}$ and absorbance was read at $\mathrm{A} 450 \mathrm{~nm}$ by a microplate reader (BioTek, Winooski, VT, USA). All samples were run in triplicate across one assay.

Each hypothalamus was immediately weighed and thawed, and homogenized in chilled 0.01 M PBS, pH 7.4, at a concentration of $100 \mathrm{mg} / \mathrm{ml}$ with a micro-glass homogenizer. The tissue was centrifuged at $1200 \boldsymbol{g}$ for 20 min in a refrigerated centrifuge. The supernatant was retained and placed at $-20^{\circ} \mathrm{C}$ until required for the ELISA. Thymulin in the serum and hypothalamus was quantified using an ELISA kit (k9810; ALPCO, Shanghai, China), and GnRH in the hypothalamus and primary cultured supernatant was quantified using a sandwich ELISA kit (orb53025; USCNK, Wuhan, China). These manipulations were carried out according to the manufacturer's instructions. The optical density (OD) at $450 \mathrm{~nm}$ was measured using a microplate reader (BioTek). The intra- and interassay coefficients of thymulin variation were $<7$ and $<12 \%$ respectively. The intra- and inter-assay coefficients of GnRH variation were $<9$ and $<15 \%$, respectively. All samples were run in triplicate across one assay. These two kits assay recognize thymulin and GnRH, thus no significant cross-reactivity or interference was observed.

\section{Immunofluorescent staining}

Hypothalami from the two groups rats were embedded in Tissue-Tek OCT compound (Sakura, Japan), and consecutive frontal plane sections were made at a thickness of $40 \mu \mathrm{m}$ using a frozen microtome (TCS CM1900, Germany). Sections were washed in 0.01 M PBS (pH 7.4) for $30 \mathrm{~min}$ and processed for dual immunofluorescent staining.

The dual immunofluorescent staining was processed with a previously described procedure (Brouns et al. 2002). Briefly, hypothalamus frozen sections were washed three times for 5 min with 0.01 M DPBS (Sigma). For GnRH and

Published by Bioscientifica Ltd. 
GFAP double labeling, hypothalamus tissue sections were incubated in an antibody mixture containing a Rabbit anti-rat GnRH I polyclonal antibody (1:300, sc-20941; Santa Cruz) and a chicken-anti-rat GFAP polyclonal antibody (1:800, ab4674; Abcam, Hangkong, China). These primary antibodies were diluted in $0.01 \mathrm{M}$ DPBS containing $10 \%$ normal goat serum and $1 \%$ Triton X-100, and incubated overnight at $4{ }^{\circ} \mathrm{C}$ with sections.

The hypothalamus tissue reactions were developed by incubation for $2 \mathrm{~h}$ at room temperature with Goat antirabbit IgG-FITC (1:300, sc-2011; Santa Cruz) and Cy5AffiniPure Goat Anti-Chicken IgY (1:500, ab97147; Abcam). The sections were washed and mounted on poly-L-lysine (Boster Company, Wuhan, China)-coated glass slides. To determine the specificity of the primary antibodies, negative staining controls were performed by consecutively incubating the sections with the normal serum that was homogenous with primary antibody (Burry 2000). The dual-labeling results were analyzed using a confocal laser scanning microscopy (Olympus, FV1000, Japan) equipped with an IX2-UCB/U-HSTR2 control systems FV10.ASW 3.0 software (Olympus, Europa SE, Japan). An argon ion laser producing light at 467 and $488 \mathrm{~nm}$, and an HeNe laser for 543 and $633 \mathrm{~nm}$ measurements, were used for the excitation of FITC and Cy5. GnRH and GFAP fluorescence intensities were calculated and analyzed according to a previously published method (Wang et al. 2009, Lim et al. 2014).

\section{Statistical analysis}

All data were expressed as the mean \pm s.E.M. and statistical analysis was carried out using SPSS 18.0 statistic analysis software. Statistical significance was determined using Student's paired $t$-test or one-way ANOVA with LSD. A value of $P<0.05$ was considered significant.

\section{Results}

\section{The GnRH antibody titer changed after immunization}

Rats injected with GnRH-tandem-OVA showed increasing titers of anti-GnRH antibodies after the last booster immunization and titers remained high until the end of the experiment. The antibody titers in rats immunized with GnRH-tandem-OVA appeared to be significantly higher than in $\mathrm{Al}(\mathrm{OH})_{3}$ adjuvant groups (Fig. 1), which produced very low antibody titers during the inoculation period. These findings suggested that the use of GnRH-tandem-OVA as an antigen was effective in stimulating an immune response.

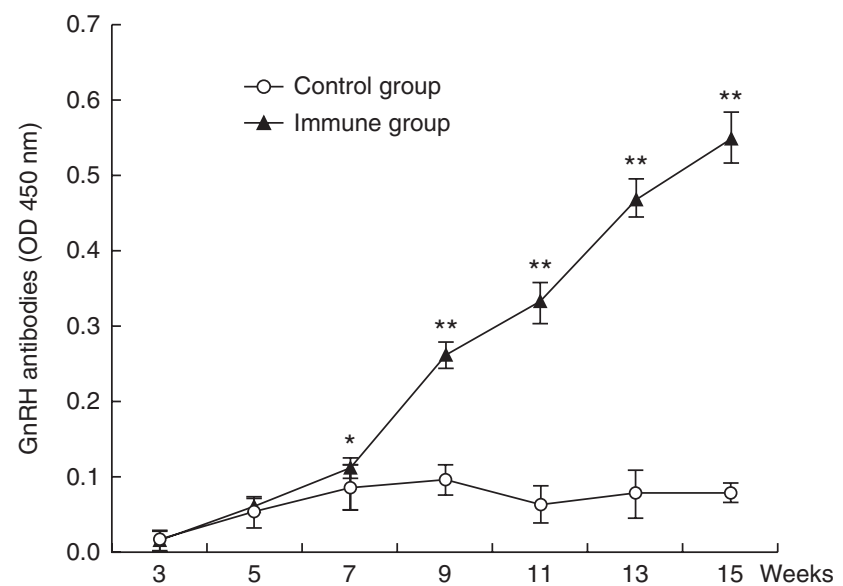

Figure 1

Detection of $\mathrm{GnRH}$ antibody titers. Measurements were taken every 2 weeks from the first immunization. Absorbance readings taken at $450 \mathrm{~nm}$ showed increased antibody titers from representative sera taken from male rats immunized with $\mathrm{GnRH}$-tandem-OVA compared with $\mathrm{Al}(\mathrm{OH})_{3}$ adjuvant control $(n=8) .{ }^{*} P<0.01, * * P<0.001$.

\section{The hormone levels in serum changed after immunization}

We investigated the testosterone, LH, FSH and thymulin levels in the serum of immunized and control rats respectively (Fig. 2A, B, C, and D). After the last booster immunization, serum testosterone concentrations were significantly reduced in the rats immunized with GnRHtandem-OVA compared with the controls (Fig. 2A). Before the second immunization, there was no significant difference in serum testosterone levels between the immune and control groups (Fig. 2A). With age, serum testosterone levels showed a distinct increase in the control rats, but significantly decreased in the immunized rats. Moreover, testosterone concentrations decreased to below the detection limit of the assay in several immunized sera from 13- to 15-week-old rats. These sample values were counted as zero and were placed on $x$-axis in Fig. 2A.

Generally, serum LH and FSH concentrations gradually increased with age in the control group, but were significantly suppressed by immunization against GnRH, although their levels increased before 9-weeks-age in the immunized group (Fig. 2B and C). LH was more sensitive to active immunization compared with FSH, because the obvious suppression of LH occurred at the second immunization (Fig. 2B). By contrast, the FSH concentration was significantly reduced at 11 weeks in the immunized rats and remained at lower levels thereafter (Fig. 2C), while LH concentration significantly decreased to its lowest level compared with other time points (Fig. 2B).

Published by Bioscientifica Ltd 

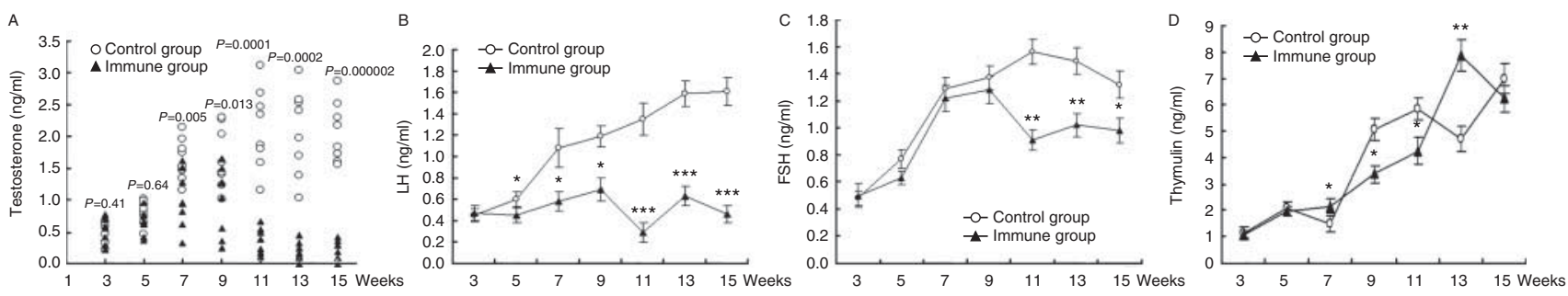

Figure 2

Levels of several hormones in serum of control and immunized rats $(n=8)$. Measurements were taken every 2 weeks from the first immunization.

(A) Testosterone levels in serum. (B) LH levels in serum. (C) FSH levels in

The variation in thymulin levels in the immunized rats was obviously different from that observed for the reproductive hormones (Fig. 2D). At the last booster immunization, the levels of thymulin were significantly increased by immunization with GnRH (Fig. 2D). Thereafter, they were significantly lower than in the controls until the end of 11 weeks-of-age. Meanwhile, the thymulin levels of the controls showed a sudden rise. Over the next 2 weeks, the thymulin concentration of the immunized rats abruptly increased and reached its highest level compared with other time points and was significantly higher than in the control group (Fig. 2D). At the end of experiment, there was no significant difference of serum thymulin levels between immunized and control rats (Fig. 2D).

\section{GnRH and thymulin levels in hypothalamus changed after immunization}

Active immunization against GnRH obviously suppressed the secretion of $\mathrm{GnRH}$ and stimulated the accumulation of thymulin in the hypothalamus (Fig. 3A and B). The GnRH concentrations in the hypothalamus were significantly lower in immunized rats compared with control rats, except at 11-weeks-old (Fig. 3A). In the immunized rat hypothalamus, thymulin levels significantly increased from 11 to 13 weeks (Fig. 3B). There were no significant differences within groups in the immunized cohort after 9 weeks and in the control group at the period of experiments (Fig. 3B). These data showed that the level of thymulin was negatively correlated with that of GnRH in the immunized rat hypothalamus.

\section{GnRH and GFAP expressions changed in the hypothalamus}

Immunofluorescent staining of $\mathrm{GnRH}$ neurons was mainly found in the paraventricular nucleus ( $\mathrm{Pa}$, Fig. 4A and $\mathrm{B}$ ), serum. (D) Thymulin levels in serum. The levels of detection for testosterone, $\mathrm{LH}$ and FSH were all $0.02 \mathrm{ng} / \mathrm{ml}$. The sensitivity of thymulin was $10.0 \mathrm{pg} / \mathrm{ml}$. ${ }^{*} P<0.05 ; * * P<0.01 ; * * * P<0.001$.

medial preoptic nucleus (MPN, Fig. 4C and D) and the arcuate nucleus (Arc, Fig. 4E and F). Moreover, the immunoreactive nerve fibers of $\mathrm{GnRH}$ were mainly a large gathering at the median eminence (ME, Fig. $4 \mathrm{G}$ and $\mathrm{H}$ ) of the rat hypothalamus, and part of the peripheral side around the third ventricle. GFAP immunoreactivity was also found in the preceding hypothalamic areas. Furthermore, the GnRH and GFAP average fluorescence intensities (AFIs) were analyzed statistical in each area of the hypothalamic nucleus (Fig. 4I and J). The AFIs of GnRH were all distinctly reduced in four hypothalamic nuclei of immunized rats (Fig. 4I). By contrast, the positive immunoreactivity of GFAP in the four areas was not consistent with that of GnRH in the immune groups. The intensity of GFAP immunostaining in the $\mathrm{Pa}$ and MPN showed no difference between the immune and control groups (Fig. 4J). GFAP immunoreactivity was significantly increased in the Arc and the ME of the immunized rats (Fig. 4J).

\section{Discussion}

GnRH and thymulin are the two keys signaling molecules that link the reproductive axis and the immune axis.
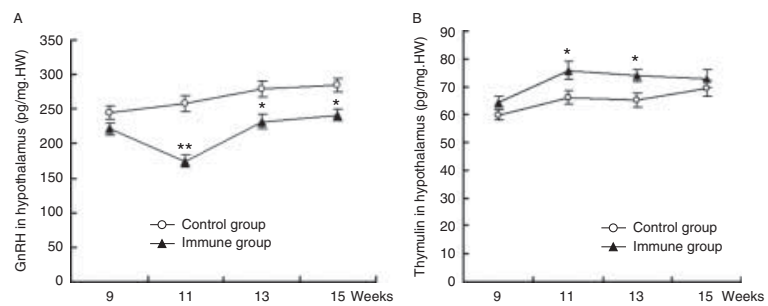

Figure 3

The levels of thymulin and GnRH in the hypothalami of control and immunized rats $(n=8)$. Measurements were taken every 2 weeks from the final booster immunization. (A) GnRH levels in homogenized hypothalamus tissue of control and immunized rats. (B) Thymulin levels in homogenized hypothalami. The sensitivities of GnRH and thymulin were 5.2 and $10.0 \mathrm{pg} / \mathrm{ml}$ respectively. HW, hypothalamus weight. ${ }^{*} P<0.05 ;{ }^{*} P<0.01$.

Published by Bioscientifica Ltd. 

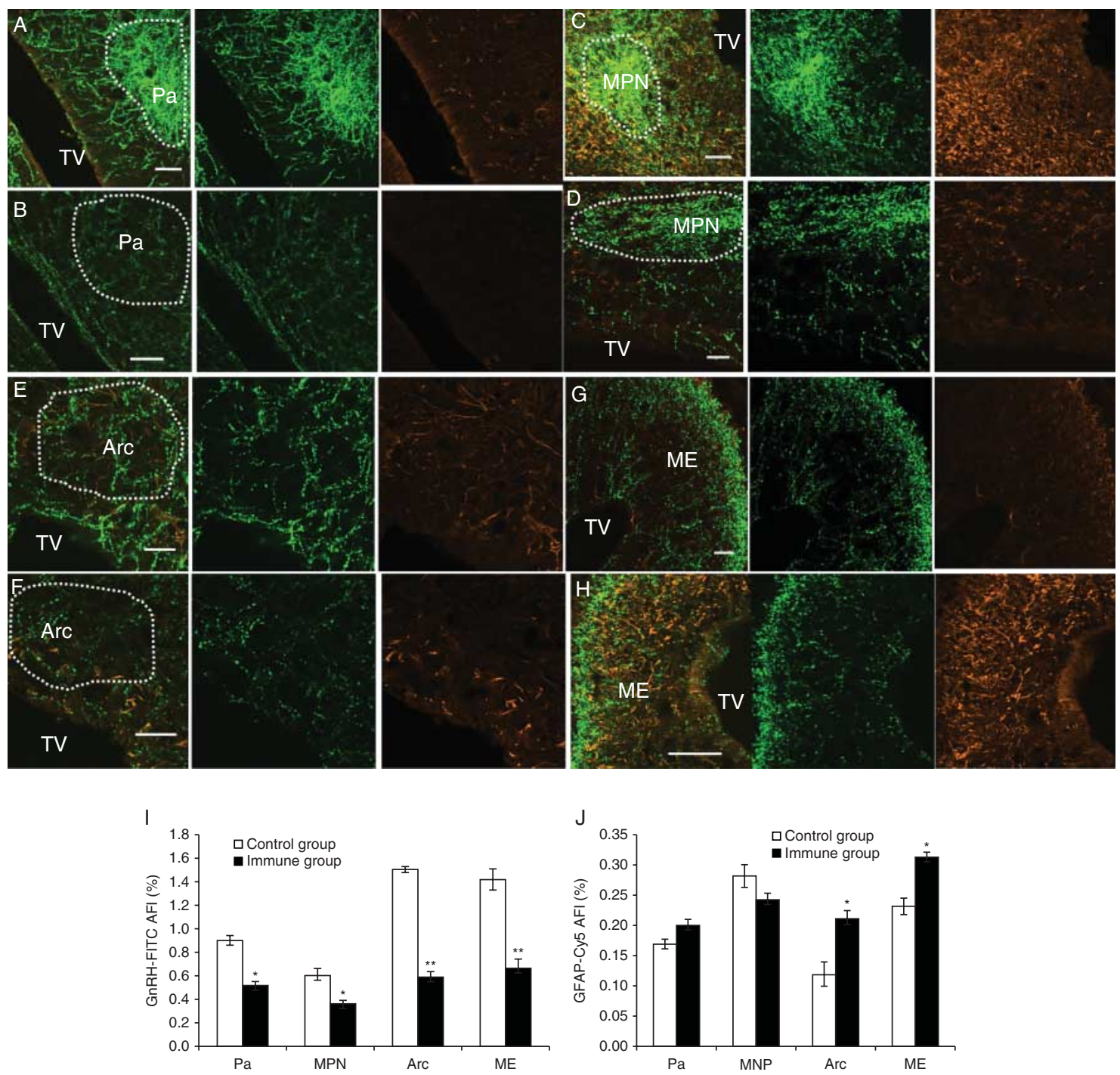

Figure 4

Protein expression of GnRH and GFAP in hypothalamic nuclei of control and immunized rats $(n=5)$. (A and B) Paraventricular nucleus (Pa) of control and immune rats respectively; (C and D) medial preoptic nucleus (MPN) respectively; ( $E$ and $F$ ) arcuate nucleus (Arc) respectively; ( $G$ and $H$ ) median eminence (ME) respectively. (I and J) Average fluorescence intensities (AFIs) of GnRH and GFAP in different areas of the hypothalamus respectively. A dotted line indicated the nuclei of the hypothalamus. Green indicates a positive reaction of GnRH with IgG-FITC, orange a positive reaction of glial

fibrillary acidic protein (GFAP) with IgY-Cy5, and their merge image was marked. TV: third ventricle, bar $=50 \mu \mathrm{m}$. AFIs of GnRH (E) and GFAP (F) in nuclei of rat hypothalami were analyzed. AFI was obtained and analyzed in two $40 \times$ object lens microscopic fields of every nucleus per hypothalamus of five rats in two treatments using the FV10.ASW 3.0 software and Image Pro-Plus 6.0 (Media Cybernetics Co., Rockville, MD, USA). Significant differences between groups were determined using an unpaired Student's $t$-test $\left(n=10\right.$; two slices per hypothalamic nuclei). ${ }^{*} P<0.05$, ${ }^{*} P<0.01$.

Immunization against GnRH is an effective method of limiting reproduction in animals (Einarsson et al. 2009, Fang et al. 2010). The method is not often used in humans, because the balance between reproduction and immunity is damaged, and the side effects remain unclear. Although there have been some studies on the mechanism of immunization, studies of the integrative mechanism are scarce.

With the increasing titer of specific antibodies produced in the immune system by immunization against GnRH, the concentration of gonadal steroids declined to a very low level, except in the first 2 weeks. The levels of gonadotropins ( $\mathrm{LH}$ and FSH) decreased sharply in the first 4 weeks, and then in the ensuing 2 weeks, their levels significantly increased, especially LH, although their levels were very low compared with the control rats.

Published by Bioscientifica Ltd 
These variations of antibody and reproductive hormones were consistent with the results of previous studies (O'Leary et al. 2008), indicating that active immunization in an animal model was successful. Meanwhile, the serum thymulin was also reduced sharply. However, the concentration increased to a high level in the ensuing 2 weeks. The present findings suggest strongly that the primary immunization effect was caused entirely by suppression of reproductive hormones, and in such a disordered endocrine internal environment, thymulin was also suppressed for about 4 weeks. The production and secretion of thymulin are stimulated directly by growth hormones and PRL, and thymulin exerts a controlling feedback effect on its own secretion (Savino et al. 1983, Goya et al. 2004). I.p. injection of anti-FTS serum markedly reduced the serum activity of endogenous thymulin. Moreover, this inhibition lasted for at least 10 days (Goya et al. 2007). The effective cycle was shorter than in rats actively immunized with GnRH, probably because of the difference in the reaction times of the thymus to passive immunization (antibody immunoneutralization) and to active immunization (antigen vaccination). Considering the multihormone control effect by the pituitary-gonadal axis on thymulin secretion, gonadotropins inhibition of thymulin secretion might act via direct action of gonadal steroids in immunized rats.

When immunization against GnRH occurred in vivo, the neuroendocrine axis was disordered and suppressed, and the gonadotropins and steroid hormones were significantly inhibited. Thus, with the reduced levels of gonadotropins and gonadal steroid, the circulating levels of thymulin also decreased in the first 4 weeks. Although, there is no direct evidence proving that gonadotropins affect thymulin secretion, gonadectomy induces a transient reduction in thymulin levels in serum (Dardenne et al. 1986). Moreover, TEC lines cultured with physiological levels of gonadal steroids showed enhanced thymulin levels in the cell supernatants (Savino et al. 1988, Goya et al. 1995). Our results and the previous data, demonstrated that circulating thymulin was directly downregulated by the repressed gonadal steroid in rats actively immunized with GnRH in the early immune period. On the other hand, testosterone is an immunosuppressant (Bilbo \& Nelson 2001) and was present at a very low levels in immunized rats. Also, the thymus endocrine function was enhanced and the secretion of thymulin in thymus was strengthened, as well as that of GnRH (Su et al. 2013). Consequently, our results showed that the level of thymulin was upregulated in the subsequent immunization period (about 2 weeks). Moreover, the effect might be in part because of the self-feedback regulation of thymulin (Cohen et al. 1986). The inhibitory effect of gonadotropins that produced the decline of thymulin in the immunized rat might be mediated by gonadal steroids, the exact mechanism of which should be determined.

As mentioned previously, in the early immunization period, the alterations in hormone the levels showed that the reproductive axis regulated thymulin production and secretion. In successive weeks (from the 4 th to the 8 th week), our data showed that thymulin feedback regulated the reproductive axis, especially the hypothalamicpituitary axis. Thus, the gradually recuperation of circulating thymulin upregulated the levels of $\mathrm{LH}$ and FSH, but not the testosterone level, although gonadotropins levels were also at a quite low level compared with controls. These results were consistent with studies that demonstrated that the thymulin exerted positive feedback regulation on $\mathrm{LH}$ and FSH in immunized rats during the late period (Reggiani et al. 2009a). However, the effect of stimulation was slight. By contrast, the accumulation of thymulin in the hypothalamus was more notable than in the serum. The concentration of thymulin in the hypothalamus of immunized rats was significantly higher than that of the control rats, except at the 8th week. Meanwhile, the GnRH concentration in the hypothalamus of immunized rats also increased significantly. These results suggested that thymulin could exert positive feedback regulation on the secretion of GnRH in the hypothalamus of rats actively immunized with GnRH. This is consistent with the hypothesis that thymulin may be part of a feedback loop acting on neuroendocrine organs, such as the hypothalamus, and modulates the stimulatory activity of GnRH on LH and FSH release from pituitary cells (Hinojosa et al. 2004, Siemion et al. 2005). In addition, thymulin plays a neuroprotective role in different areas of the brain that interact with a set of cytokines (Safieh-Garabedian et al. 2011). Thus, the effect of upregulation on GnRH in hypothalamus may be, at least in part, explained by the neuroprotective role of thymulin. Indeed, active immunization against GnRH disordered the function and even remodeled the structure of hypothalamus. Furthermore, the average immunofluorescence density showed that the synthesis and secretion of GnRH neurons were suppressed in the immune hypothalamus. However, it is unclear by what mechanism thymulin upregulates GnRH in the immune hypothalamus: whether it involves plastic rearrangements of glial-GnRH neurons adhesiveness or the production of growth factors acting via receptors with tyrosine kinase activity remains to be determined (Mullier et al. 2010, Heja et al. 2012).

Published by Bioscientifica Ltd 
Hypothalamic astrocytes release a variety of neuroactive factors, including TGF $\alpha$, prostaglandin E2 and their receptors forming a signaling pathway that is essential for the glial mediation in GnRH release (Buchanan et al. 2000, Clasadonte et al. 2011). The AFIs of GnRH were all low in four areas of the hypothalamus from rats immunized with GnRH. Moreover, the inhibitory effect was more significant in the Arc and ME. The regional discrepancy in immunoactive GnRH may be largely explained by the fact that the Arc that is the key area of the steroid hormone feedback regulation on GnRH (Yeo \& Herbison 2014). In immunized male rats, the fairly low level of testosterone negatively feedback regulates the production of $\mathrm{GnRH}$ neurons in the Arc instead of the Pa and MPN, which contain many GnRH cell bodies to regulate other hypophysiotropic hormone releasing hormones besides GnRH (Van Vugt et al. 1997, Rivalland et al. 2006). Likewise, the release of GnRH was significantly suppressed via reduction in the conveyance of GnRH to its nerve terminals in the ME of immunized rats (Glanowska \& Moenter 2015).

Interestingly, regional specificity was also shown by GFAP positive immunoreaction in the immune hypothalamus. In the Arc and ME, the AFIs of GFAP were significantly higher than in the control rats. By contrast, AFIs were similar in the Pa and MPN between the two treatments. These changes were associated with altered astrocyte-neuron contacts and synaptic remodeling in immunized rats. The stimulation of hormones, especially gonadal steroids, on the activities of astrocytes in the Arc and ME (Blutstein et al. 2009, Yin et al. 2009, Yeo \& Herbison 2014), at least demonstrated that testosterone reduced plastic rearrangements of glial-GnRH neurons adhesiveness. By contrast, testosterone increased the number of astrocytes in the hippocampus reduced GFAP expression and stimulated the reactive astrocyte hypertrophy in the infarct area of the rat brain (Pan et al. 2005, Emamian et al. 2010). The results confirmed that the effect of testosterone on astrocytes is independent of the location and the physiological status. The activities of astrocytes in the Arc and ME may be also be regulated by other signaling pathways of peripheral small-molecules, such as thymulin. After all, without the blood-brain barrier, circulating molecules were taken up by astrocytes in Arc and ME (Cheunsuang \& Morris 2005, Morita \& Miyata 2013). Thus, it is unclear whether the effect and regulation of thymulin on GnRH is direct or mediated by astrocytes. These results suggested that the secretion and release of GnRH to modulate reproduction in the Arc and ME was regulated not only via the synaptic connectivity between astrocytes and GnRH neurons modulated by the feedback regulation of reproductive hormones, but also via a specific molecular signaling pathway.

In summary, the current study demonstrated that reproductive hormones and thymulin were distinctly suppressed by immunization against GnRH. In the late period of immunization, the immunosuppression of androgens and the increase of LH were abolished, and the circulating thymulin level increased significantly. We showed that thymulin could stimulate GnRH neurons development and secretion, not only by direct contact with GnRH, but also mediated via astrocytes in different regions of the hypothalamus.

\section{Declaration of interest}

The authors declare that there is no conflict of interest that could be perceived as prejudicing the impartiality of the research reported.

\section{Funding}

This work was supported by grants from the Natural Science Foundation of Anhui Education Department (KJ2014A077), the Breeding Discipline Backbone Project of Anhui Agriculture University (2014XKPY-26), and the National Natural Science Foundation of China (31472096).

\section{References}

Bach JF \& Dardenne M 1989 Thymulin, a zinc-dependent hormone. Medical Oncology and Tumor Pharmacotherapy 6 25-29. (doi:10.1007/ BF02985220)

Bilbo SD \& Nelson RJ 2001 Sex steroid hormones enhance immune function in male and female Siberian hamsters. American Journal of Physiology. Regulatory, Integrative and Comparative Physiology 280 R207-R213.

Blutstein T, Baab PJ, Zielke HR \& Mong JA 2009 Hormonal modulation of amino acid neurotransmitter metabolism in the arcuate nucleus of the adult female rat: a novel action of estradiol. Endocrinology $\mathbf{1 5 0}$ 3237-3244. (doi:10.1210/en.2008-1701)

Brouns I, Van Nassauw L, Van Genechten J, Majewski M, Scheuermann DW, Timmermans JP \& Adriaensen D 2002 Triple immunofluorescence staining with antibodies raised in the same species to study the complex innervation pattern of intrapulmonary chemoreceptors. Journal of Histochemistry and Cytochemistry 50 575-582. (doi:10.1177/ 002215540205000415)

Brown OA, Sosa YE, Dardenne M, Pleau JM \& Goya RG 2000 Studies on the gonadotropin-releasing activity of thymulin: changes with age. Journals of Gerontology. Series A, Biological Sciences and Medical Sciences 55 B170-B176. (doi:10.1093/gerona/55.4.B170)

Buchanan CD, Mahesh VB \& Brann DW 2000 Estrogen-astrocyteluteinizing hormone-releasing hormone signaling: a role for transforming growth factor- $\beta(1)$. Biology of Reproduction 62 1710-1721. (doi:10.1095/biolreprod62.6.1710)

Burry RW 2000 Specificity controls for immunocytochemical methods. Journal of Histochemistry and Cytochemistry 48 163-166. (doi:10.1177/ 002215540004800201)

Cheunsuang O \& Morris R 2005 Astrocytes in the arcuate nucleus and median eminence that take up a fluorescent dye from the circulation

Published by Bioscientifica Ltd. 
express leptin receptors and neuropeptide Y Y1 receptors. Glia 52 228-233. (doi:10.1002/glia.20239)

Clasadonte J, Poulain P, Hanchate NK, Corfas G, Ojeda SR \& Prevot V 2011 Prostaglandin $\mathrm{E}(2)$ release from astrocytes triggers gonadotropinreleasing hormone $(\mathrm{GnRH})$ neuron firing via EP2 receptor activation. PNAS 108 16104-16109. (doi:10.1073/pnas.1107533108)

Cohen S, Berrih S, Dardenne M \& Bach JF 1986 Feedback regulation of the secretion of a thymic hormone (thymulin) by human thymic epithelial cells in culture. Thymus 8 109-119.

Cook RB, Popp JD, Kastelic JP, Robbins S \& Harland R 2000 The effects of active immunization against $\mathrm{GnRH}$ on testicular development, feedlot performance, and carcass characteristics of beef bulls. Journal of Animal Science 78 2778-2783.

Dardenne M, Papiernik M, Bach JF \& Stutman O 1974 Studies on thymus products. 3. Epithelial origin of the serum thymic factor. Immunology 27 299-304.

Dardenne M, Pleau JM, Nabarra B, Lefrancier P, Derrien M, Choay J \& Bach JF 1982 Contribution of zinc and other metals to the biological activity of the serum thymic factor. PNAS 79 5370-5373. (doi:10.1073/ pnas.79.17.5370)

Dardenne M, Savino W, Duval D, Kaiserlian D, Hassid J \& Bach JF 1986 Thymic hormone-containing cells. VII. Adrenals and gonads control the in vivo secretion of thymulin and its plasmatic inhibitor. Journal of Immunology 136 1303-1308.

Dardenne M, Savino W, Gagnerault MC, Itoh T \& Bach JF 1989 Neuroendocrine control of thymic hormonal production. I. Prolactin stimulates in vivo and in vitro the production of thymulin by human and murine thymic epithelial cells. Endocrinology 125 3-12. (doi:10.1210/ endo-125-1-3)

Einarsson S, Andersson K, Wallgren M, Lundström K \& Rodriguez-Martinez H 2009 Short- and long-term effects of immunization against gonadotropin-releasing hormone, using Improvac, on sexual maturity, reproductive organs and sperm morphology in male pigs. Theriogenology 71 302-310. (doi:10.1016/j.theriogenology.2008.07.022)

Emamian S, Naghdi N, Sepehri H, Jahanshahi M, Sadeghi Y \& Choopani S 2010 Learning impairment caused by intra-CA1 microinjection of testosterone increases the number of astrocytes. Behavioural Brain research 208 30-37. (doi:10.1016/j.bbr.2009.11.004)

Fang F, Li H, Liu Y, Zhang Y, Tao Y, Li Y, Cao H, Wang S, Wang L \& Zhang X 2010 Active immunization with recombinant GnRH fusion protein in boars reduces both testicular development and mRNA expression levels of GnRH receptor in pituitary. Animal Reproduction Science 119 275-281. (doi:10.1016/j.anireprosci.2010.01.003)

Gastinel LN, Dardenne M, Pleau JM \& Bach JF 1984 Studies on the zinc binding site to the serum thymic factor. Biochimica et Biophysica Acta 797 147-155. (doi:10.1016/0304-4165(84)90116-8)

Glanowska KM \& Moenter SM 2015 Differential regulation of GnRH secretion in the preoptic area (POA) and the median eminence (ME) in male mice. Endocrinology 156 231-241. (doi:10.1210/en.2014-1458)

Gore AC 2002 GnRH: The Master Molecule of Reproduction. New York, NY, USA: Springer Science + Business Media. (doi:10.1007/978-1-4757-3565-9)

Goya RG, Gagnerault MC, Sosa YE \& Dardenne M 1995 Reduced ability of hypothalamic and pituitary extracts from old mice to stimulate thymulin secretion in vitro. Mechanisms of Ageing and Development $\mathbf{8 3}$ 143-154. (doi:10.1016/0047-6374(95)01619-B)

Goya RG, Brown OA, Pleau JM \& Dardenne M 2004 Thymulin and the neuroendocrine system. Peptides 25 139-142. (doi:10.1016/j.peptides.2003.11.002)

Goya RG, Reggiani PC, Vesenbeckh SM, Pleau JM, Sosa YE, Console GM, Schade R, Henklein P \& Dardenne M 2007 Thymulin gene therapy prevents the reduction in circulating gonadotropins induced by thymulin deficiency in mice. American Journal of Physiology. Endocrinology and Metabolism 293 E182-E187. (doi:10.1152/ajpendo. 00085.2007)

Heja L, Nyitrai G, Kekesi O, Dobolyi A, Szabo P, Fiath R, Ulbert I, Pal-Szenthe B, Palkovits M \& Kardos J 2012 Astrocytes convert network excitation to tonic inhibition of neurons. BMC Biology $\mathbf{1 0} 26$. (doi:10.1186/1741-7007-10-26)

Hinojosa L, Garcia L, Dominguez R, Romano MC, Damian-Matsumura PG, Castillo L \& Rosas P 2004 Effects of thymulin and GnRH on the release of gonadotropins by in vitro pituitary cells obtained from rats in each day of estrous cycle. Life Sciences 76 795-804. (doi:10.1016/j.lfs.2004. 07.017)

Jinshu X, Jingjing L, Duan P, Zheng Z, Ding M, Jie W, Rongyue C, Zhuoyi H $\&$ Roque RS 2005 A synthetic gonadotropin-releasing hormone $(\mathrm{GnRH})$ vaccine for control of fertility and hormone dependent diseases without any adjuvant. Vaccine 23 4834-4843. (doi:10.1016/j.vaccine. 2005.05.010)

Junco JA, Basalto R, Fuentes F, Bover E, Reyes O, Pimentel E, Calzada L, Castro MD, Arteaga N, Lopez Y et al. 2008 Gonadotrophin releasing hormone-based vaccine, an effective candidate for prostate cancer and other hormone-sensitive neoplasms. Advances in Experimental Medicine and Biology 617 581-587. (doi:10.1007/978-0-387-69080-3_60)

Ladd A, Walfield A, Tsong YY \& Thau R 1995 Active immunization against LHRH alone or combined with LHRH-analogue treatment impedes growth of androgen-dependent prostatic carcinoma. American Journal of Reproductive Immunology 34 200-206. (doi:10.1111/j.16000897.1995.tb00939.x)

Lim WL, Soga T \& Parhar IS 2014 Maternal dexamethasone exposure during pregnancy in rats disrupts gonadotropin-releasing hormone neuronal development in the offspring. Cell and Tissue Research $\mathbf{3 5 5}$ 409-423. (doi:10.1007/s00441-013-1765-9)

Ma YJ, Berg-von der Emde K, Rage F, Wetsel WC \& Ojeda SR 1997 Hypothalamic astrocytes respond to transforming growth factor- $\alpha$ with the secretion of neuroactive substances that stimulate the release of luteinizing hormone-releasing hormone. Endocrinology 138 19-25. (doi:10.1210/enco.138.1.4863)

Marchetti B, Gallo F, Farinella Z, Tirolo C, Testa N, Romeo C \& Morale MC 1998 Luteinizing hormone-releasing hormone is a primary signaling molecule in the neuroimmune network. Annals of the New York Academy of Sciences $\mathbf{8 4 0}$ 205-248. (doi:10.1111/j.1749-6632.1998.tb09564.x)

Marchetti B, Gallo F, Farinella Z, Tirolo C, Testa N, Caniglia S \& Morale MC 2000 Gender, neuroendocrine-immune interactions and neuron-glial plasticity. Role of luteinizing hormone-releasing hormone (LHRH) Annals of the New York Academy of Sciences 917 678-709. (doi:10.1111/ j.1749-6632.2000.tb05434.x)

Martines E, Reggiani PC, Schwerdt JI, Goya RG \& Console G 2011 Neonatal thymulin gene therapy in nude mice: effects on the morphology of the pituitary corticotrope population. Histology and Histopathology 26 471-479.

Miller LA, Gionfriddo JP, Fagerstone KA, Rhyan JC \& Killian GJ 2008 The single-shot GnRH immunocontraceptive vaccine (GonaCon) in white-tailed deer: comparison of several GnRH preparations. American Journal of Reproductive Immunology 60 214-223. (doi:10.1111/j.16000897.2008.00616.x)

Morale MC, Batticane N, Bartoloni G, Guarcello V, Farinella Z, Galasso MG \& Marchetti B 1991 Blockade of central and peripheral luteinizing hormone-releasing hormone (LHRH) receptors in neonatal rats with a potent LHRH-antagonist inhibits the morphofunctional development of the thymus and maturation of the cell-mediated and humoral immune responses. Endocrinology 128 1073-1085. (doi:10.1210/ endo-128-2-1073)

Morita S \& Miyata S 2013 Accessibility of low-molecular-mass molecules to the median eminence and arcuate hypothalamic nucleus of adult mouse. Cell Biochemistry and Function 31 668-677. (doi:10.1002/cbf.2953)

Mullier A, Bouret SG, Prevot V \& Dehouck B 2010 Differential distribution of tight junction proteins suggests a role for tanycytes in bloodhypothalamus barrier regulation in the adult mouse brain. Journal of Comparative Neurology 518 943-962. (doi:10.1002/cne.22273)

Ojeda SR, Lomniczi A \& Sandau US 2008 Glial-gonadotrophin hormone $(\mathrm{GnRH})$ neurone interactions in the median eminence and the control

Published by Bioscientifica Ltd. 
of GnRH secretion. Journal of Neuroendocrinology 20 732-742. (doi:10.1111/j.1365-2826.2008.01712.x)

O'Leary S, Lloyd ML, Shellam GR \& Robertson SA 2008 Immunization with recombinant murine cytomegalovirus expressing murine zona pellucida 3 causes permanent infertility in BALB/c mice due to follicle depletion and ovulation failure. Biology of Reproduction 79 849-860. (doi:10.1095/biolreprod.108.067884)

Pan Y, Zhang H, Acharya AB, Patrick PH, Oliver D \& Morley JE 2005 Effect of testosterone on functional recovery in a castrate male rat stroke model. Brain Research 1043 195-204. (doi:10.1016/j.brainres.2005.02.078)

Paxinos G \& Watson C 2000 The Rat Brain in Stereotaxic Coordinates, 2nd Edn. San Diego, CA, USA: Academic Press. (doi:10.1016/01662236(87)90017-8)

Reggiani PC, Morel GR, Console GM, Barbeito CG, Rodriguez SS, Brown OA, Bellini MJ, Pleau JM, Dardenne M \& Goya RG 2009a The thymusneuroendocrine axis: physiology, molecular biology, and therapeutic potential of the thymic peptide thymulin. Annals of the New York Academy of Sciences 1153 98-106. (doi:10.1111/j.1749-6632.2008.03964.x)

Reggiani P, Martines E, Ferese C, Goya R \& Console G 2009b Morphological restoration of gonadotrope population by thymulin gene therapy in nude mice. Histology and Histopathology 24 729-735.

Reggiani PC, Barbeito CG, Zuccolilli GO, Console GM, Flamini AM, Dardenne M \& Goya RG 2012 Neonatal thymulin gene therapy prevents ovarian dysgenesis and attenuates reproductive derangements in nude female mice. Endocrinology 153 3922-3928. (doi:10.1210/en. 2012-1183)

Rivalland ET, Tilbrook AJ, Turner AI, Iqbal J, Pompolo S \& Clarke IJ 2006 Projections to the preoptic area from the paraventricular nucleus, arcuate nucleus and the bed nucleus of the stria terminalis are unlikely to be involved in stress-induced suppression of GnRH secretion in sheep. Neuroendocrinology 84 1-13. (doi:10.1159/000096372)

Safieh-Garabedian B, Jabbur SJ, Dardenne M \& Saade NE 2011 Thymulin related peptide attenuates inflammation in the brain induced by intracerebroventricular endotoxin injection. Neuropharmacology 60 496-504. (doi:10.1016/j.neuropharm.2010.11.004)

Savino W, Dardenne M \& Bach JF 1983 Thymic hormone containing cells. III. Evidence for a feed-back regulation of the secretion of the serum thymic factor (FTS) by thymic epithelial cells. Clinical and Experimental Immunology 52 7-12.
Savino W, Bartoccioni E, Homo-Delarche F, Gagnerault MC, Itoh T \& Dardenne M 1988 Thymic hormone containing cells - IX. Steroids in vitro modulate thymulin secretion by human and murine thymic epithelial cells. Journal of Steroid Biochemistry 30 479-484. (doi:10.1016/ 0022-4731(88)90148-3)

Savino W, Gagnerault MC, Bach JF \& Dardenne M 1990 Neuroendocrine control of thymic hormonal production. II. Stimulatory effects of endogenous opioids on thymulin production by cultured human and murine thymic epithelial cells. Life Sciences 46 1687-1697. (doi:10.1016/0024-3205(90)90384-4)

Siemion IZ, Kluczyk A \& Cebrat M 2005 The peptide molecular links between the central nervous and the immune systems. Amino Acids 29 161-176. (doi:10.1007/s00726-005-0231-8)

Su S, Fang F, Liu Y, Li Y, Ren C, Zhang Y \& Zhang X 2013 The compensatory expression of reproductive hormone receptors in the thymus of the male rat following active immunization against GnRH. General and Comparative Endocrinology 185 57-66. (doi:10.1016/j.ygcen.2013.01.013)

Van Vugt DA, Piercy J, Farley AE, Reid RL \& Rivest S 1997 Luteinizing hormone secretion and corticotropin-releasing factor gene expression in the paraventricular nucleus of rhesus monkeys following cortisol synthesis inhibition. Endocrinology 138 2249-2258. (doi:10.1210/endo. 138.6.5171)

Wang CJ, Zhou ZG, Holmqvist A, Zhang H, Li Y, Adell G \& Sun XF 2009 Survivin expression quantified by Image Pro-Plus compared with visual assessment. Applied Immunohistochemistry \& Molecular Morphology 17 530-535. (doi:10.1097/PAI.0b013e3181a13bf2)

Weesner GD, Becker BA \& Matteri RL 1997 Expression of luteinizing hormone-releasing hormone and its receptor in porcine immune tissues. Life Sciences 61 1643-1649. (doi:10.1016/S0024-3205(97)00769-8)

Wise T \& Ford JJ 1999 Effects of the thymic peptide thymulin on in vitro and in vivo testicular steroid concentrations in white composite and Meishan boars. Journal of Animal Science 77 2240-2251.

Yeo SH \& Herbison AE 2014 Estrogen-negative feedback and estrous cyclicity are critically dependent upon estrogen receptor- $\alpha$ expression in the arcuate nucleus of adult female mice. Endocrinology $\mathbf{1 5 5}$ 2986-2995. (doi:10.1210/en.2014-1128)

Yin W, Wu D, Noel ML \& Gore AC 2009 Gonadotropin-releasing hormone neuroterminals and their microenvironment in the median eminence: effects of aging and estradiol treatment. Endocrinology 150 5498-5508. (doi:10.1210/en.2009-0679)

Received in final form 21 May 2015

Accepted 27 May 2015

Accepted Preprint published online 27 May 2015
(C) 2015 Society for Endocrinology Printed in Great Britain 